\title{
Maternal and paternal carriage of the annexin A5 M2 haplotype: a possible risk factor for recurrent implantation failure (RIF)
}

\author{
Nina Rogenhofer ${ }^{1} \cdot$ Arseni Markoff $^{2} \cdot$ Xenia Ennerst $^{1} \cdot$ Nadja Bogdanova $^{2} \cdot$ Christian Thaler $^{1}$
}

Received: 7 July 2020 / Revised: 30 September 2020 / Accepted: 12 October 2020 / Published online: 24 November 2020

(C) The Author(s) 2020

\begin{abstract}
Objective This study was carried out to determine the potential role of the M2/ANXA5 haplotype as a risk factor for recurrent implantation failure (RIF). Carriage of the M2/ANXA5 haplotype that induces prothrombotic changes has been implicated in failure of early pregnancies and placenta-mediated complications (preeclampsia, IUGR, preterm birth).

Material and methods In the present case control study, 63 couples (females and males) with RIF presenting for IVF/ICSI to the Fertility Center of [masked] were analyzed. RIF was defined as $\geq 4$ consecutive failed ART-transfers of $\geq 4$ blastocysts or $\geq 8$ cleavage-stage embryos of optimal quality and maternal age $\leq 41$. Fertile female controls $(n=90)$ were recruited from the same center. Population controls $(n=533)$ were drafted from the PopGen biobank, UKSH Kiel.

Results Couples carrying the M2/ANXA5 haplotype turned out to have a significantly increased relative risk (RR) for RIF. Compared with female fertile controls, RR was 1.81 with $p=0.037$ (OR 2.1,95\%CI 1.0-4.3) and RR was 1.70, with $p=0.004$ (OR 2.0, 95\%CI 1.2-3.1) compared with population controls (15.4\% M2 carriers). Male partners were comparable with RIF females for M2/ANXA5 haplotypes ( $28.6 \%$ vs. $23.8 \%, p=0.54)$. RIF females compared with population controls had a RR of $1.55(p=0.09)$ and RIF males compared with population controls had a RR of $1.9(p=0.01)$. Couples with $\geq 7$ failed transfers showed a RR of $1.82(p=0.02)$ compared with population controls.

Conclusion Our findings suggest that maternal as well as paternal M2/ANXA5 haplotype carriages are risk factors for RIF. These results allow new insights into the pathogenesis of RIF and might help to identify relevant risk groups.
\end{abstract}

Keywords M2 Haplotype · Annexin · Recurrent implantation failure

\section{Introduction}

Recurrent implantation failure (RIF) is determined when morphologically good quality embryos repeatedly fail to implant after numerous IVF/ICSI treatment attempts [1-5].

There are several variations to the criteria for defining RIF [2]. Some definitions include the numbers of failed ART

Nina Rogenhofer and Arseni Markoff contributed equally to this work.

Nina Rogenhofer

nina.rogenhofer@med.uni-muenchen.de

1 Division of Gynecological Endocrinology and Reproductive Medicine, Department of Gynaecology and Obstetrics, University Hospital of the Ludwig-Maximilians-University, Marchioninistrasse 15, 81377 Munich, Germany

2 Institute of Human Genetics, UKM and WWU, Muenster, Germany cycles and the numbers of transferred embryos. For example, Polanski et al. assess RIF as $\geq 2$ consecutive unsuccessful transfers with $\geq 4$ embryos or 2 blastocysts of high quality [6]. Others include female age as an additional criterion [1, 3-7], such as the European Society for Human Reproduction and the Embryology (ESHRE) PGD Consortium [4, 5]. They define RIF as $\geq 3$ transfers in women under 37 years or, respectively, $\geq 2$ transfers in women above 37 years after transfers of 10 good quality embryos. Considering the current success rate of an ART attempt, the number and quality of embryos transferred, and the female age, we defined RIF as $\geq 4$ failed consecutive ART transfers of $\geq 4$ blastocysts or $\geq 8$ cleavage stage embryos of good quality in women $\leq 41$ years.

Human implantation is a complex process requiring synchrony between a healthy embryo that should have the potential to implant and a functionally competent and receptive endometrium [8]. A successful development is the result of a coordinated "cross-talk" between the embryo and the 
endometrium, which leads to the apposition, attachment, and invasion of the embryo into the receptive uterine stroma [2, 8]. Any abnormality will result in an implantation failure.

Despite extensive efforts and research on fundamental causes for RIF, the understanding of this condition is still limited [9]. Frequently, the embryo and its ploidy status have been considered $[9,10]$. Failure of implantation due to embryonic causes is associated with either genetic abnormalities or other factors that impair the embryo to develop in utero, to hatch, and to implant $[2,3]$. Likewise, maternal factors were suggested to play an essential role for RIF [1-3, 10]. For example, uterine abnormalities $[2,11,12]$, thrombophilias [3, 13-16], immunological factors [1-5], the antiphospholipid syndrome, parental genetic disorders [3, 10], and endometrial factors, particularly the receptivity with the window of implantation, were proposed [4, 17-22]. Nevertheless, the majority of RIF cases still remain unexplained $[1,2,10]$.

Since 2007, much work has been accumulated on a newly identified hereditary thrombophilic genetic factor, the 'M2 haplotype' of the annexin A5 (ANXA5) gene. Indeed, we and others identified the M2 haplotype associated with obstetric pathologies such as gestational hypertension, preeclampsia [23-27], fetal growth restriction, preterm birth [26, 28-30], antiphospholipid syndrome [31], and most incriminatory recurrent pregnancy losses (RPL) [32]. Moreover, in our previous studies, we confirmed risks of maternal M2/ANXA5 haplotype and identified the paternal carrier status as an equal risk factor for RPL and obstetric complications [23, 33].

The M2/ANXA5 haplotype results in a reduced expression of ANXA5 products usually expressed at the apical surface of the syncytiotrophoblast (SCT) $[25,26,34]$, facing the intervillous space and floated with maternal blood [35]. Thus, ANXA5 accomplishes its anticoagulant function necessary for the hemodynamic balance in the placenta and pregnancy, thereby decreasing phospholipid availability for the cascade of coagulation factors [36-39]. As a successful implantation requires a balance of pro- and anticoagulatory mechanism at the embryo-maternal interface and within the placenta, ANXA5 is indispensable for the process of implantation. Anti-annexin A5 antibodies (anti-ANXA5) have been identified to influence and even inhibit the essential functions of the ANXA5, particularly affecting implantation. Matsubayashi et al. demonstrated that RIF patients produce anti-ANXA5 significantly more often than controls $(8.3 \%$ vs. $1.1 \%, p<0.05$ ) and consequently postulate anti-ANXA5 antibodies as risk factor for RIF [40]. Currently, there is only one multicenter study by Fishel et al. analyzing the M2/ANXA5 haplotype in infertility couples undergoing ART procedure [41]. They reported a M2 carrier status of $44 \%$ in IVF couples ( $n=157$; one or both partners), $24 \%$ of females, $26 \%$ of males, and $37 \%$ of couples with unexplained infertility [41]. In spite of these intruiging results, the relevance of M2/ANXA5 for RIF has not yet been studied.
Therefore, the primary objective of this study was to investigate, whether the maternal and/or the paternal M2/ANXA5 carriage are risk factors for RIF. As a second objective, we aimed to find new insights into the pathogenesis of RIF to identify relevant risk groups. With regard to these goals, we investigated the prevalence of M2/ANXA5 in a well-defined cohort of RIF couples and compared them to two independent control groups.

\section{Materials and methods}

\section{Definitions}

In this present case control study, RIF was defined as $\geq 4$ consecutive failed ART-transfers of $\geq 4$ blastocysts or $\geq 8$ cleavagestage embryos of optimal quality and maternal age $\leq 41$.

\section{Study populations and controls}

The study population of 63 couples ( 63 females and 63 males) with a history of recurrent implantation failure was recruited between May 2016 and May 2019 in the Division of Gynecological Endocrinology and Reproductive Medicine of the [masked for blinded review] University. All individuals studied were from European origin, mainly German. After clarification and written informed consent, blood was drawn and DNA was extracted from white blood cells using the QIAmp DNA blood mini kit (Qiagen, Hilden, Germany) and stored in $100-\mu \mathrm{l}$ aliquots at $-20^{\circ} \mathrm{C}$ for further analyses.

Biographic and historic data of RIF couples (RIF females and RIF males) and [masked for blinded review] fertile controls are illustrated in Table 1. The study cohort was composed as follows: 11 couples already terminated the fertility treatment and were contacted for the purpose of this study; 52 couples were still in treatment. Indications for the fertility treatment are illustrated in Fig. 1.

In total, 309 embryo transfers (ET) were performed, and altogether, 556 embryos were transferred. Out of the 309 ET, 154 transfers were fresh ET with 155 (53.5\%) day 5 transferred blastocysts and $136(46.7 \%)$ day 3 transferred cleavage stages. The remaining 155 transfers were frozen-thawed ET with totally $195(73.6 \%)$ transferred blastocysts (d5 transfers) and $70(26.4 \%)$ cleavage stages ( $\mathrm{d} 3$ transfers). Regarding the number of transferred embryos, 62 (11.2\%) single ET and 494 (88.8\%) double ET were carried out.

The study group was compared with two independent control groups:

(1) 90 fertile women with inconspicuous timespan to conception ( $<10$ months), uncomplicated pregnancies, no gestational pathologies, at least one spontaneous term delivery of a healthy normal weight singleton, and no 
Table 1 Biographic and historic data of the RIF couple subclassified in females and males vs. [masked for blinded review] fertile controls

\begin{tabular}{|c|c|c|c|c|}
\hline & RIF females $(n=63)$ & RIF males $(n=63)$ & $\begin{array}{l}\text { [masked for blinded review] } \\
\text { fertile controls }\end{array}$ & $p$ \\
\hline Age (year) & $35 \pm 3(26-41)$ & $39 \pm 5(27-50)$ & $34 \pm 5(21-41)$ & 0.049 \\
\hline Body mass index $\left(\mathrm{kg} / \mathrm{m}^{2}\right)$ & $23 \pm 2(19-30)$ & - & - & - \\
\hline Pregnancies $(n)$ & $0.2 \pm 0.5(0-2)$ & - & $2(1-5)$ & $<0.0001$ \\
\hline Deliveries $(n)$ & $0.0 \pm 0.2(0-1)$ & - & $2(1-5)$ & $<0.0001$ \\
\hline Miscarriages $(n)$ & $0.1 \pm 0.4(0-2)$ & --- & 0 & $<0.0001$ \\
\hline Ectopic pregnancies $(n)$ & $0.0 \pm 0.2(0-1)$ & --- & 0 & $<0.0001$ \\
\hline
\end{tabular}

$n$ number, $R I F$ recurrent implantation failure

miscarriages. This fertile control group was aged between 18 and 41 years and showed a BMI of 19 to 30 $\mathrm{kg} / \mathrm{m}^{2}$ according to the study population. They were recruited between May 2016 and May 2019 in the outpatient clinic of the Department of Gynecology and Obstetrics, [masked for blinded review] University ([masked for blinded review] controls). Biographic data and gestational history of the [masked for blinded review] controls are shown in Table 1.

(2) Previously recruited German control group representing a population control sample drafted from the PopGen biobank at the University Clinic Schleswig-Holstein Kiel $(n=533)$ [42]. The PopGen population controls were from Northwest Germany, federal state of Schleswig-Holstein, and consisted of healthy subjects identified through official population registers. The sample used in this study consisted of about equal numbers of men and women, distributed among the three age groups (18-30, 30-50, 50-80 years).

\section{Study criteria and RIF screening}

The study criteria (inclusion and exclusion criteria) are summarized in Table 2.

All patients had undergone an extensive diagnostic work up to identify any potential cause for RIF before study inclusion. If any potential reason was detected, it was eliminated, if this was possible and a benefit could be expected; otherwise patients were excluded. In brief, the following factors were screened: uterine anomalies were clarified by hysteroscopy. Endometrial receptivity analysis (ERA) was carried out by endometrial biopsy in a non-treatment cycle before embryo transfer to identify the window of implantation. Endocrinologic dysfunctions (polycystic ovary syndrome according to the Rotterdam criteria [43], hyperprolactinemia, hyperandrogenemia, thyroidal dysfunctions such as hypo-/ hyperthyreosis and thyroid autoantibodies), autoimmune disorders (antinuclear antibodies $>1: 240$ ), inherited thrombophilias (factor V-Leiden mutation, the prothrombin $20210 \mathrm{G}>\mathrm{A}$ ), and deficiencies in coagulation factors (protein $\mathrm{C}$, protein $\mathrm{S}$, factor XII, antithrombin) were excluded. An antiphospholipid syndrome was ruled out according to the international consensus
Fig. 1 Indications for fertility treatment of the RIF couples subdivided in female and male indications. RIF: recurrent implantation failure. Created with CorelDraw Home\&Student X8

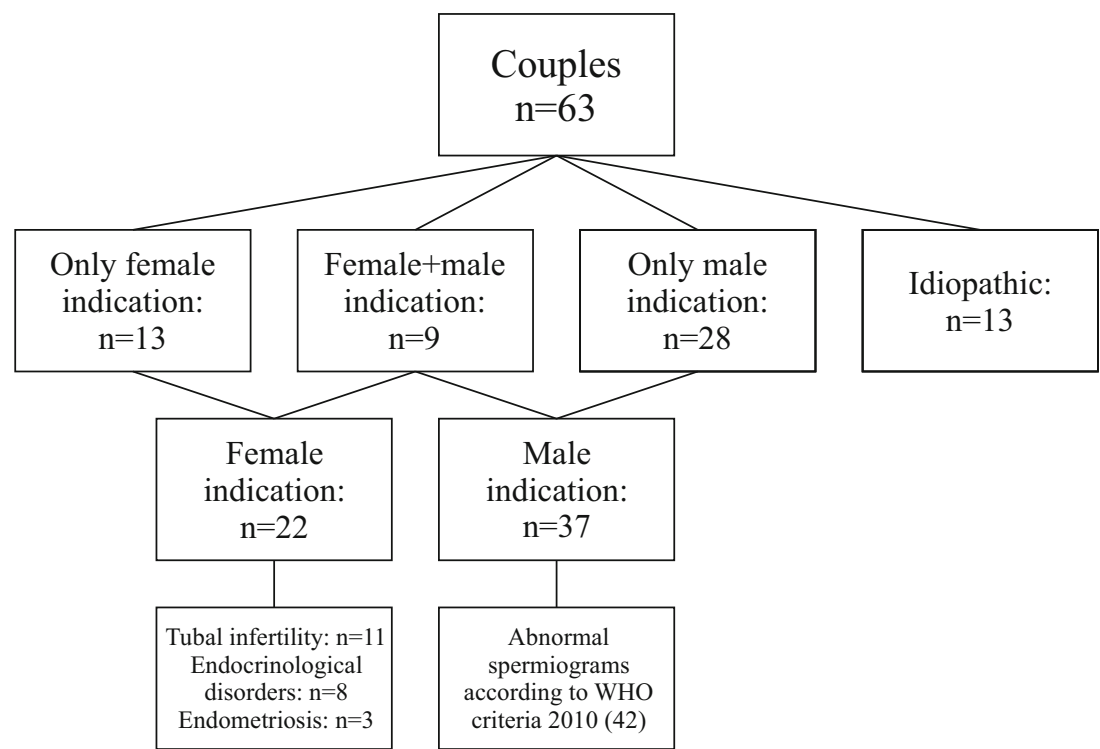


Table 2 Study criteria

Signed informed consent

Age $\geq 18 \leq 41$ years

RIF definition fulfilled

Unexplained RIF

European origin

BMI $>19<30 \mathrm{~kg} / \mathrm{m}^{2}$

Non-smoker

No intake of medications for systematic diseases

No infectious diseases

$R I F$ recurrent implantation failure, $B M I$ body mass index (calculated as weight in kilograms divided by the square of height in meters)

statement on an update of the classification criteria for definite antiphospholipid syndrome [44]. Parental genetic disorders were clarified by genetic counseling and karyotype testing of the couples. In case of a chromosomal anomaly, a preimplantation genetic screening (PGS) was offered and carried out after approval by a nominated and qualified ethic committee.

\section{Ethical approval}

The study complied with the ethical guidelines of the institutions involved and was approved of the Review Board of the [masked for blinded review] University (IRB 238-16). Informed consent was obtained from all patients and controls. The criteria of strengthening the reporting of observational studies in epidemiology [45] were observed as far as applicable.

\section{Genotyping and statistical analysis}

The extracted DNA was genotyped through amplicon sequencing as previously described [46]. The genotypes were recorded in table format and coded for further usage. Odds ratios (OR) with $95 \%$ confidence intervals $(\mathrm{CI})$ were calculated by using the FREQ procedure intrinsic to the SAS statistical software package, version 9 (SAS Institute, Cary, NC, USA). Departures from the Hardy-Weinberg equilibrium were computed by a Markov Chain Monte Carlo (MCMC) implementation of an exact test, as part of the Genepop package [47].

\section{Results}

In total, 63 couples with RIF were investigated and compared with 90 fertile female controls ([masked for blinded review] controls) and with 533 population controls (PopGen controls). The study group was in Hardy-Weinberg equilibrium for the ANXA5 haplotypes (RIF couples: MCMC $P=.2090$, RIF females: MCMC $P=.3378$, RIF males: MCMC $P=.4703$ ) as well as both control groups [masked for blinded review] controls (MCMC $P=.1150$ ) and PopGen controls (MCMC $P=.409)$, respectively. The genetic frequency of M2 (Table 3) was found to be considerably higher in RIF patients (RIF couples: 0.143 , RIF females: 0.127, RIF males: 0.159) than in [masked for blinded review] controls (0.083) and population controls (0.082).

M2 carriers presented a 1.8-fold elevated risk for RIF (OR $2.1,95 \%$, CI 1.0-4.3) compared with noncarriers. In comparison with the PopGen control group $(n=533)$, similar results were obtained (Table 4). Results regarding RR and OR of the M2/ANXA5 carriership of RIF couples, subclassified in RIF females and RIF males compared with [masked for blinded

Table 3 Genotype frequencies of ANXA5 gene promoter haplotypes in European RIF couples, RIF females and RIF males, and different control groups

\begin{tabular}{|c|c|c|c|c|c|c|c|c|c|c|}
\hline \multirow{2}{*}{$\begin{array}{l}\text { Index } \\
\text { Genotype }\end{array}$} & \multicolumn{2}{|c|}{ RIF couples } & \multicolumn{2}{|c|}{ RIF females } & \multicolumn{2}{|l|}{ RIF males } & \multicolumn{2}{|c|}{$\begin{array}{l}\text { [masked for blinded review] } \\
\text { fertile controls }\end{array}$} & \multicolumn{2}{|c|}{ PopGen controls } \\
\hline & Observed & Expected $^{\mathrm{a}}$ & Observed & Expected $^{\mathrm{a}}$ & Observed & Expected $^{\mathrm{a}}$ & Observed & Expected $^{\mathrm{a}}$ & Observed & Expected $^{\mathrm{a}}$ \\
\hline $\mathrm{N} / \mathrm{N}$ & $75(59.5)$ & 73.8 & $41(65.1)$ & 41.2 & $34(54.0)$ & 32.8 & $62(68.9)$ & 60 & 415 (77.9) & 413.3 \\
\hline N/M1 & 15 (11.9) & 17.7 & $6(9.5)$ & 6.5 & $9(14.2)$ & 10.9 & 15 (16.7) & 14.8 & $35(65.7)$ & 47.8 \\
\hline M1/M1 & $3(2.4)$ & 1.0 & $1(1.6)$ & 0.2 & $2(3.2)$ & 0.8 & 0 & 0.8 & $1(0.2)$ & 1.5 \\
\hline $\mathrm{N} / \mathrm{M} 2, \mathrm{M} 1 / \mathrm{M} 2^{\mathrm{b}}$ & $30(23.8)$ & 31.0 & $14(22.2)$ & 14.1 & $16(25.2)$ & 17.0 & $11(12.2)$ & 13.8 & $77(14.4)$ & 79.9 \\
\hline M2/M2 & $3(2.4)$ & 2.5 & $1(1.6)$ & 1.0 & $2(3.2)$ & 1.5 & $2(2.2)$ & 0.6 & $5(0.9)$ & 1.4 \\
\hline Total & 126 & 126 & 63 & 63 & 63 & 63 & 90 & 90 & 533 & 533 \\
\hline
\end{tabular}

Note: Values are number (percentage)

$N$ wild type, $M 1$ M1-haplotype, $M 2$ M2-haplotype

${ }^{a}$ Expected: genotype frequency expected at Hardy-Weinberg equilibrium, calculated with the Genepop package

${ }^{\mathrm{b}}$ Genotype M1/M2 was only observed in two RIF males, in three [masked for blinded review] fertile controls and five PopGen controls 
Table 4 Relative risks and odds ratios of the M2 carriage of RIF couples, RIF females and RIF males compared with [masked for blinded review] fertile controls and PopGen controls

\begin{tabular}{|c|c|c|c|c|}
\hline & & $\mathrm{RR}[95 \% \mathrm{CI}]$ & OR $[95 \% \mathrm{CI}]$ & $p$ \\
\hline \multirow[t]{2}{*}{ RIF couples } & [masked for blinded review] fertile controls & $1.81[1.01-3.25]$ & $2.10[1.03-4.27]$ & 0.037 \\
\hline & PopGen controls & $1.70[1.19-2.42]$ & $1.95[1.23-3.10]$ & 0.004 \\
\hline \multirow[t]{2}{*}{ RIF females } & [masked for blinded review] fertile controls & $1.65[0.84-3.22]$ & $1.85[0.81-4.23]$ & 0.141 \\
\hline & PopGen controls & $1.55[0.95-2.51]$ & $1.72[0.92-3.21]$ & 0.087 \\
\hline \multirow[t]{2}{*}{ RIF males } & [masked for blinded review] fertile controls & $1.98[1.05-3.73]$ & $2.37[1.06-5.29]$ & 0.027 \\
\hline & PopGen controls & $1.86[1.20-2.88]$ & $2.20[1.21-3.99]$ & 0.008 \\
\hline \multirow[t]{2}{*}{ RIF couples with idiopathic infertility } & [masked for blinded review] fertile controls & $2.13[0.99-4.58]$ & $2.63[0.95-7.29]$ & 0.057 \\
\hline & PopGen controls & $2.00[1.09-3.68]$ & $2.44[1.03-5.81]$ & 0.043 \\
\hline \multirow[t]{2}{*}{ Higher-grade RIF ( $\geq 7$ failed transfers)) } & [masked for blinded review] fertile controls & $1.94[0.99-3.79]$ & $2.30[0.98-5.40]$ & 0.052 \\
\hline & PopGen controls & $1.82[1.12-2.96]$ & $2.14[1.10-4.14]$ & 0.021 \\
\hline
\end{tabular}

$R I F$ recurrent implantation failure, $R R$ relative risk, $O R$ odds ratio, $C I$ confidence interval

review] fertile controls and PopGen controls, are illustrated in Table 4.

RIF couples as well as RIF males showed significantly higher RR and OR for M2/ANXA5 carriership compared with both control groups (RIF couples vs. [masked for blinded review] fertile controls: RR 1.81; $p=0.037$, respectively, vs. PopGen controls: RR 1.70; $p=0.004$; RIF males vs. PopGen controls: RR 1.86; $p=0.008$ ) (Table 4).

Subanalysis revealed 15 RIF females (1 homozygote) and 18 RIF male partners (2 homozygotes) being M2 carriers (Table 3). Thus, the genetic risk transmitted by maternal and paternal alleles turns out to be comparable. As men were showing higher AF, the sample size was too small $(n=63)$ to draw further conclusions.

Interestingly, RIF couples with idiopathic infertility and RIF couples with higher grade RIF ( $\geq 7$ failed transfers) showed significantly increased RR and OR compared with PopGen controls (RR 2.0, OR 2.44; $p=0.043$, respectively, RR 1.82, OR 2.14; $p=0.021$ ).

Couples with idiopathic infertility presented M2/ANXA5 non-significantly more often than couples with identified indication for ART (30.8\% vs. $25.0 \%, p=0.55$ ).

\section{Discussion}

Our study strongly supports an association of the M2/ANXA5 haplotype with RIF. The obtained results suggest an active role of the haplotype in RIF events. Our findings of equal maternal (23.8\%) and paternal (28.6\%) M2 carriership suggest embryonic and possibly maternal factors.

Highly ordered 2D arrays of ANXA5 have been found to be indispensable for membrane repair in murine perivascular cells $[48,49]$. Further investigations confirmed this finding in human cyto- and syncytiotrophoblasts [50]. Additional studies showed that 2D arrays of ANXA5 are essentially involved in the regulation of trophoblast aggregation to form syncytia. Hence, this 2D network of ANXA5 is essential for successful fusion of cells [51]. Villous cytotrophoblasts fuse throughout pregnancy to form multinucleated syncytia on chorionic villi that extends into the maternal placental blood circulation to form an interphase allowing effective exchange of gases and nutrients in the intervillous chamber [52]. Moreover, these multinucleated syncytia produce and secrete pregnancyspecific hormones [53], such as hCG [54], that are of pivotal importance for implantation, placentation, and subsequently, a successful pregnancy. Also, the cellular fusion and membrane repair events are of importance for a successful embryonal implantation at the forming of the cell-to-cell interphase composed of extraembryonic and endometrial receptive membranes to trigger the necessary programs of early placentation. It would be then logical to propose that paternal (embryonic) and maternal factors would have about equal bearing in these processes. A reduced expression of ANXA5 in carriers of the M2 haplotype may disturb cell fusion and membrane repair ultimately leading to implantation failure.

To our knowledge, this is the first study on the role of M2/ ANXA5 in RIF. Previously, it has been demonstrated that the haplotype was a risk factor for infertility in IVF cohorts [41, 55]. In this context, the authors demonstrated in 2014 that IVF-treated couples $(n=157)$ with infertility had significantly increased M2 carriage, whereas maternal and paternal carriages impose an equal risk [41]. In the light of its importance for patients with RPL and potentially implantation failure, the study has assessed the incidence of carrier status for the M2/ ANXA5 haplotype in both the female and male of couples with at least one failed IVF cycle. In 314 patients (157 couples), $44 \%$ of couples (one or both partners), $24 \%$ of females, $26 \%$ of males, and $37 \%$ of couples with unexplained infertility were M2 carriers [41]. This rather high incidence inspired further more dedicated studies on specific patient populations and the value of post embryo-transfer therapy. Couples $(n=$ 
77) with one or both partners carrying M2/ANXA5 showed a correlation of this haplotype with an adverse IVF outcome [55]. A pragmatic, multicenter, prospective cohort study of M2/ANXA5 haplotype screening, and low molecular weight heparin (LMWH) treatment following embryo transfer in 103 IVF couples positive for M2 was conducted. They were compared with a group of 1000 contemporaneous randomly selected unscreened and untreated couples undergoing assisted conception, from which 103 matched control couples were extracted. The primary outcome measure was live birth incidence. Secondary outcomes were results following ET and live birth outcome by gender and M2 carriage and allelic dose influence. In the result, the tested and treated cohort of M2/ ANXA5 carriers reached a similar live birth rate (37.9\%) per ET cycle compared with both, the more fertile comparison group (38.5\%) and the 103 matched controls (33.0\%). Significantly more treated male carrier only couples had a live birth of $58.3 \%$ vs. $25.0 \%(p=0.045)$ versus female M2. Thus, pragmatic M2/ANXA5 screening and treatment with LMWH in couples undergoing IVF were associated with similar outcome to couples with more beneficial prognostic factors. The difference in live birth outcome for treated male-only carrier couples may be consistent with an additional maternal thrombophilic factor that may adversely affect pregnancy, although other mechanisms, such as LMWH dosage effect, are feasible. This study suggested that LMWH treatment should be started prior to clinical pregnancy.

A very recent report identified alternative means of supplementing anticoagulation, through elevated ANXA5 expression [56]. Physiological micromolar $\mathrm{Zn}^{2+}$ stimulated ANXA5 transcription, raising ANXA5 protein expression and surface abundance on choriocarcinoma human placental cells (BeWo) and human umbilical vein endothelial cells (HUVEC), thus resulting in extended coagulation times. In this study, $\mathrm{Zn}^{2+}$-fed AnxA5 functionally deficient pregnant mice exhibited a trend to increase litter size when primiparous that grew similarly to wild-type progeny in subsequent pregnancies. A raised AnxA5 signal upon $\mathrm{Zn}^{2+}$ treatment was confirmed in murine placentae. Micromolar $\mathrm{Zn}^{2+}$ stimulated ANXA5 expression in cell culture directly and attenuated RPL in AnxA5 genetically deficient mice, without notable toxicity effects.

However, currently, there is no consistent definition of RIF. Some authors include the number of failed ART-cycles and the number of transferred embryos as criteria for defining RIF. Others, additionally, include the female age $[1,3-7,10]$. The ESHRE guideline addresses female age $(<37$ years and $>$ 37 years), however, without an upper limit. As clinical pregnancy rate per embryo transfer decreases from $20.8 \%$ in women at the age of 41 years to $17.7 \%$ at the age of 42 and the rate of aneuploid oocytes increases from about $57 \%$ to $68 \%$ [57, 58], we included the female age and set the cutoff at the female age of $\leq 41$ years. Considering the current success rate of an
ART attempt, the number and quality of embryos transferred as well as the female age, we defined RIF as $\geq 4$ failed consecutive ART transfers of $\geq 4$ blastocysts or $\geq 8$ cleavage stage embryos of good quality in women $\leq 41$ years. With these more refined RIF criteria, we think we can substantially increase the significance of our study.

Furthermore, to discuss the advantages of our novel approach, we refer to the well-defined study group including 63 infertile couples of 63 women as well as 63 men compared with two control groups: one unselected, large population control of 533 females and males in equal parts and one fertile, female control group of 90 participants. All investigated individuals were from European origin; thus, possible interference caused by ethnic differences was excluded. Additionally, to meet the strict study criteria, all patients had undergone an extensive diagnostic work-up for selecting unexplained RIF, including genetic counseling and karyotype testing. A possible weakness of this study should be mentioned at this point, that routine pre-implantation genetic screening was not performed due to legal restrictions and therefore the genetic ploidy status of the transferred embryos remained unknown.

As a matter of fact, multiple failed cycles can leave couples frustrated and desperate for explanations. It is therefore necessary to determine the etiologies of RIF in order to propose new and beneficial solutions for these patients.

Our findings suggest that maternal and paternal M2/ ANXA5 haplotype carriages are risk factors for RIF. These results allow new insights into the pathogenesis of RIF and might help to identify relevant risk groups. Further studies are needed to confirm our assumption. As well, therapeutic options have to be identified and established.

\section{Conclusion}

Deficiency of ANXA5 through maternal or paternal carriership of the M2 haplotype is proposed as a risk factor for recurrent implantation failure.

This finding represents a possible explanation for implantation failure after IVF/ICSI as well as for the absence of spontaneous conceptions. Our results provide new insights into the pathogenesis of RIF and could be used to identify patients at risk.

Funding Open Access funding enabled and organized by Projekt DEAL. This study was supported by a PI grant from the German Research Society (DFG), MA-6288/1-1 to AM.

Open Access This article is licensed under a Creative Commons Attribution 4.0 International License, which permits use, sharing, adaptation, distribution and reproduction in any medium or format, as long as you give appropriate credit to the original author(s) and the source, provide a link to the Creative Commons licence, and indicate if changes were made. The images or other third party material in this article are included in the article's Creative Commons licence, unless indicated otherwise in a 
credit line to the material. If material is not included in the article's Creative Commons licence and your intended use is not permitted by statutory regulation or exceeds the permitted use, you will need to obtain permission directly from the copyright holder. To view a copy of this licence, visit http://creativecommons.org/licenses/by/4.0/.

\section{References}

1. Bashiri A, Halper KI, Orvieto R. Recurrent implantation failureupdate overview on etiology, diagnosis, treatment and future directions. Reprod Biol Endocrinol. 2018;16:121.

2. Simon A, Laufer N. Assessment and treatment of repeated implantation failure (RIF). J Assist Reprod Genet. 2012;29:1227-39.

3. Simon A, Laufer N. Repeated implantation failure. Clinical approach. Fertil Steril. 2012;97:1039-43.

4. Tan BK, Vandekerckhove P, Kennedy R, Keay SD. Investigation and current management of recurrent IVF treatment failure in the UK. BJOG. 2005;112:773-80.

5. Thornhill AR, de Die-Smulders CE, Geraedts JP, Harper JC, Harton GL, Lavery SA, et al. ESHRE PGD Consortium Best practice guidelines for clinical preimplantation genetic diagnosis (PGD) and preimplantation genetic screening (PGS). Human Reproduct (Oxford, England). 2005;20:35-48.

6. Polanski LT, Baumgarten MN, Quenby S, Brosens J, Campbell BK, Raine-Fenning NJ. What exactly do we mean by 'recurrent implantation failure'? A systematic review and opinion. Reprod BioMed Online. 2014;28:409-23.

7. Rinehart J. Recurrent implantation failure. Definition. J Assist Reprod Genet. 2007;24:284-7.

8. Fukui Y, Hirota Y, Matsuo M, Gebril M, Akaeda S, Hiraoka T, et al. Uterine receptivity, embryo attachment, and embryo invasion. Multistep processes in embryo implantation. Reproduct Med Biol. 2019;18:234-40.

9. Zohni KM, Gat I, Librach C. Recurrent implantation failure. A comprehensive review. Minerva Ginecol. 2016;68:653-67.

10. Macklon N. Recurrent implantation failure is a pathology with a specific transcriptomic signature. Fertil Steril. 2017;108:9-14.

11. Timeva T, Shterev A, Kyurkchiev S. Recurrent implantation failure. The role of the endometrium. J Reproduct Infertil. 2014;15: 173-83.

12. Safdarian L, Najmi Z, Aleyasin A, Aghahosseini M, Rashidi M, Asadollah S. Recurrent IVF Failure and Hereditary Thrombophilia. Iranian J Reproduct Med. 2014;12:467-70.

13. Grandone E, Tiscia G, Colaizzo D, Chinni E, Pisanelli D, Bafunno $\mathrm{V}$, et al. Role of the M2 haplotype within the annexin A5 gene in the occurrence of pregnancy-related venous thromboembolism. Am J Obstet Gynecol. 2010;203:461.e1-5.

14. Azem F, Many A, Ben Ami I, Yovel I, Amit A, Lessing JB, et al. Increased rates of thrombophilia in women with repeated IVF failures. Human Reproduct (Oxford, England). 2004;19:368-70.

15. Coulam CB, Jeyendran RS, Fishel LA, Roussev R. Multiple thrombophilic gene mutations are risk factors for implantation failure. Reprod BioMed Online. 2006;12:322-7.

16. Qublan HS, Eid SS, Ababneh HA, Amarin ZO, Smadi AZ, AlKhafaji FF, et al. Acquired and inherited thrombophilia. Implication in recurrent IVF and embryo transfer failure. Human Reproduct (Oxford, England). 2006;21:2694-8.

17. Valdes CT, Schutt A, Simon C. Implantation failure of endometrial origin. It is not pathology, but our failure to synchronize the developing embryo with a receptive endometrium. Fertil Steril. 2017;108:15-8.
18. Simón C, Pellicer A, Polan ML. Interleukin-1 system crosstalk between embryo and endometrium in implantation. Human Reproduct (Oxford, England). 1995;10 Suppl 2:43-54.

19. Valbuena D, Jasper M, Remohí J, Pellicer A, Simón C. Ovarian stimulation and endometrial receptivity. Human Reproduct (Oxford, England). 1999;14 Suppl 2:107-11.

20. Revel A. Defective endometrial receptivity. Fertil Steril. 2012;97: 1028-32.

21. Bouet P-E, El Hachem H, Monceau E, Gariépy G, Kadoch I-J, Sylvestre C. Chronic endometritis in women with recurrent pregnancy loss and recurrent implantation failure. Prevalence and role of office hysteroscopy and immunohistochemistry in diagnosis. Fertil Steril. 2016;105:106-10.

22. Kasius JC, Fatemi HM, Bourgain C, Sie-Go DMDS, Eijkemans RJC, Fauser BC, et al. The impact of chronic endometritis on reproductive outcome. Fertil Steril. 2011;96:1451-6.

23. Rogenhofer N, Nienaber LRM, Amshoff LC, Bogdanova N, Petroff D, Wieacker P, et al. Assessment of M2/ANXA5 haplotype as a risk factor in couples with placenta-mediated pregnancy complications. J Assist Reprod Genet. 2018;35:157-63.

24. Gourvas V, Soulitzis N, Konstantinidou A, Dalpa E, Koukoura O, Koutroulakis D, et al. Reduced ANXA5 mRNA and protein expression in pregnancies complicated by preeclampsia. Thromb Res. 2014;133:495-500.

25. Ota $\mathrm{S}$, Miyamura $\mathrm{H}$, Nishizawa $\mathrm{H}$, Inagaki $\mathrm{H}$, Inagaki $\mathrm{A}$, Inuzuka $\mathrm{H}$, et al. Contribution of fetal ANXA5 gene promoter polymorphisms to the onset of pre-eclampsia. Placenta. 2013;34:1202-10.

26. Chinni E, Tiscia GL, Colaizzo D, Vergura P, Margaglione M, Grandone E. Annexin V expression in human placenta is influenced by the carriership of the common haplotype M2. Fertil Steril. 2009;91:940-2.

27. Shu F, Sugimura M, Kanayama N, Kobayashi H, Kobayashi T, Terao T. Immunohistochemical study of annexin $\mathrm{V}$ expression in placentae of preeclampsia. Gynecol Obstet Investig. 2000;49:17-23.

28. Aranda F, Udry S, Perés Wingeyer S, Amshoff LC, Bogdanova N, Wieacker P, et al. Maternal carriers of the ANXA5 M2 haplotype are exposed to a greater risk for placenta-mediated pregnancy complications. J Assist Reprod Genet. 2018;35:921-8.

29. Tiscia G, Colaizzo D, Chinni E, Pisanelli D, Sciannamè N, Favuzzi $\mathrm{G}$, et al. Haplotype M2 in the annexin A5 (ANXA5) gene and the occurrence of obstetric complications. Thromb Haemost. 2009; 102: 309-13.

30. Sifakis S, Soufla G, Koukoura O, Soulitzis N, Koutroulakis D, Maiz N, et al. Decreased annexin A5 mRNA placental expression in pregnancies complicated by fetal growth restriction. Thromb Res. 2010;125:326-31.

31. Rand JH, Wu XX, Guller S, Gil J, Guha A, Scher J, et al. Reduction of annexin-V (placental anticoagulant protein-I) on placental villi of women with antiphospholipid antibodies and recurrent spontaneous abortion. Am J Obstet Gynecol. 1994;171:1566-72.

32. Ang K-C, Bogdanova N, Markoff A, Ch'ng ES, Tang TH. Association between M2/ANXA5 haplotype and repeated pregnancy loss. A meta-analysis. Fertil Steril. 2019;111:971-981.e2.

33. Rogenhofer N, Engels L, Bogdanova N, Tüttelmann F, Markoff A, Thaler C. Paternal and maternal carriage of the annexin A5 M2 haplotype are equal risk factors for recurrent pregnancy loss. A pilot study. Fertil Steril. 2012;98:383-8.

34. Markoff A, Gerdes S, Feldner S, Bogdanova N, Gerke V, Grandone E. Reduced allele specific annexin A5 mRNA levels in placentas carrying the M2/ANXA5 allele. Placenta. 2010;31:937-40.

35. Krikun G, Lockwood CJ, Wu XX, Zhou XD, Guller S, Calandri C, et al. The expression of the placental anticoagulant protein, annexin $\mathrm{V}$, by villous trophoblasts. Immunolocalization and in vitro regulation. Placenta. 1994;15:601-12. 
36. Bogdanova N, Baleva M, Kremensky I, Markoff A. The annexin A5 protective shield model revisited. Inherited carriage of the M2/ ANXA5 haplotype in placenta as a predisposing factor for the development of obstetric antiphospholipid antibodies. Lupus. 2012;21:796-8.

37. Rand JH, Wu XX. Antibody-mediated disruption of the annexin-V antithrombotic shield. A new mechanism for thrombosis in the antiphospholipid syndrome. Thromb Haemost. 1999;82:649-55.

38. Römisch J, Seiffge D, Reiner G, Pâques EP, Heimburger N. In-vivo antithrombotic potency of placenta protein 4 (annexin V). Thromb Res. 1991;61:93-104.

39. Thiagarajan P, Tait JF. Binding of annexin V/placental anticoagulant protein I to platelets. Evidence for phosphatidylserine exposure in the procoagulant response of activated platelets. J Biol Chem. 1990;265:17420-3.

40. Matsubayashi H, Arai T, Izumi S, Sugi T, McIntyre JA, Makino T. Anti-annexin $\mathrm{V}$ antibodies in patients with early pregnancy loss or implantation failures. Fertil Steril. 2001;76:694-9.

41. Fishel S, Patel R, Lytollis A, Robinson J, Smedley M, Smith P, et al. Multicentre study of the clinical relevance of screening IVF patients for carrier status of the annexin A5 M2 haplotype. Reprod BioMed Online. 2014;29:80-7.

42. Krawczak M, Nikolaus S, von Eberstein H, Croucher PJP, El Mokhtari NE, Schreiber S. PopGen. Population-based recruitment of patients and controls for the analysis of complex genotypephenotype relationships. Commun Genet. 2006;9:55-61.

43. Revised 2003 consensus on diagnostic criteria and long-term health risks related to polycystic ovary syndrome. Fertility and Sterility 2004;81;19-25.

44. Miyakis S, Lockshin MD, Atsumi T, Branch DW, Brey RL, Cervera $\mathrm{R}$, et al. International consensus statement on an update of the classification criteria for definite antiphospholipid syndrome (APS). J Thromb Haemost. 2006;4:295-306.

45. von Elm E, Altman DG, Egger M, Pocock SJ, Gøtzsche PC, Vandenbroucke JP. The strengthening the reporting of observational studies in epidemiology (STROBE) statement. Guidelines for reporting observational studies. Int J Surg. 2014;12:1495-9.

46. Bogdanova N, Horst J, Chlystun M, Croucher PJP, Nebel A, Bohring A, et al. A common haplotype of the annexin A5 (ANXA5) gene promoter is associated with recurrent pregnancy loss. Hum Mol Genet. 2007;16:573-8.
47. Raymond M, Rousset F. GENEPOP (Version 1.2). Population Genetics Software for Exact Tests and Ecumenicism. J Heredity Jg. 1995;86 Nr.3 S:248-9.

48. Bouter A, Gounou C, Bérat R, Tan S, Gallois B, Granier T, et al. Annexin-A5 assembled into two-dimensional arrays promotes cell membrane repair. Nat Commun. 2011;2:270.

49. Bouter A, Carmeille R, Gounou C, Bouvet F, Degrelle SA, EvainBrion D, et al. Review. Annexin-A5 and cell membrane repair. Placenta. 2015;36 Suppl 1:S43-9.

50. Carmeille R, Degrelle SA, Plawinski L, Bouvet F, Gounou C, EvainBrion D, et al. Annexin-A5 promotes membrane resealing in human trophoblasts. Biochim Biophys Acta. 1853;2015:2033-44.

51. Degrelle SA, Gerbaud P, Leconte L, Ferreira F, Pidoux G. Annexin-A5 organized in 2D-network at the plasmalemma eases human trophoblast fusion. Sci Rep. 2017;7:42173.

52. Benirschke K, Burton GJ, Baergen RN. Pathology of the human placenta. 6th ed. Berlin: Springer; 2012.

53. Eaton B, Contractor S. In: Redman CW, Sargent IL, Starkey PM, editors. In vitro assessment of trophoblast receptors and placental transport mechanisms. London: Blackwell Scientific Publication; 1993. p. 471-503.

54. Jameson JL, Hollenberg AN. Regulation of chorionic gonadotropin gene expression. Endocr Rev. 1993;14:203-21.

55. Fishel S, Baker D, Elson J, Ragunath M, Atkinson G, Shaker A, et al. Precision Medicine in Assisted Conception. A multicenter observational treatment cohort study of the annexin A5 M2 haplotype as a biomarker for antithrombotic treatment to improve pregnancy outcome. EBioMedicine. 2016;10:298-304.

56. Danisik H, Bogdanova N, Markoff A. Micromolar zinc in annexin A5 anticoagulation as a potential remedy for RPRGL3-associated recurrent pregnancy loss. Reproduct Sci (Thousand Oaks, Calif). 2019;26:348-56.

57. Deutsches IVF-Register (D·I-R) e. V. 2018. D.I.R-Jahrbuch 2018. Journal für Reproduktionsmedizin und Endokrinologie. www. deutsches-ivf-register.de.

58. Pellestor F, Andréo B, Arnal F, Humeau C, Demaille J. Maternal aging and chromosomal abnormalities. New data drawn from in vitro unfertilized human oocytes. Hum Genet. 2003;112:195-203.

Publisher's note Springer Nature remains neutral with regard to jurisdictional claims in published maps and institutional affiliations. 